\title{
Apreciación del Poeta Stephen Crane
}

I

Dos palabras

A la memoria de

STEPHEN CRANE,

nacido en Newark el 1 de noviembre de 1871 .

Consiguió, antes de su temprana muerte

el 5 de junio de 1900 .

fama internacional como escritor de ficciones.

$\mathrm{Su}$ novela $L a$ divisa toja del valor sirvío de modelo a quienes escribieron después

sobre las emociones de los hombres en los campos de batalla.

Sus versos y sus deliciosos cuentos de juventud anticiparon fuertes tendencias posteriores

en la literatura americana.

El poder de su obra le ganó la admiración

de un ancho círculo de lectores y críticos.

Elevado por la junta de maestros apoyada por los discípulos de las escuelas públicas de Newark, el Día de Newark, 7 de noviembre de 192 I.

En conmemoración del aniversario quincuagésimo del nacimiento del autor.

Así reza -vertida al castellano- la inscripción que lleva el monumento conmemorativo del escritor norteamericano Stephen Crane, de fama mundial. "El bote abierto" es bien conocido y técni- 
camente sobresaliente, como lo son varios otros cuentos suyos; $L a$ divisa roja del valor, novela psicológica, ha sido llamada la mejor novela de guerra del mundo; y entre ellos, por su extensión, está su famosísimo estudio Maggie, muchacha de las calles, 1 novela condensada de un realismo chocante en su día y muy imitado después. Mucho se ha escrito acerca de los alcances de Crane en el campo de la prosa; menos atención le han prestado los críticos a sus poesías. Es poeta de pro. $Y$ sucede que, mientras algunos aprecian en mucho su influencia poética, otros la niegan casi por completo; todavía queda, pues, por fijar su verdadero sitio con respecto a "la poesía nueva" de la primera parte del presente siglo, así como su influencia en el uso del verso libre propiamente dicho - verso rítmico, pero sin rima ni acentuación regular.

Es el propósito de este artículo dar a conocer traducidos al castellano algunos poemitas de Crane y dar una idea de las circunstancias de su composición y del autor.

Tenemos ciento nueve poemas de Crane, ninguno largo, muchos brevísimos. De ellos, sesenta y ocho aparecieron en 1895, bajo el título The Black Riders and Other Lines (Los jinetes negros); veintisiete se publicaron en 1899 con el título $W$ ar Is Kind (La guerra es benigna); diez más hallaron sitio en el mismo tomito (publicado por Frederic A. Stockes) con el título Intriga; 2 tres se hallaron en 1928, y están impresos en los poemas recogidos; y uno más llegó a publicarse en 1932, con el título "Un poema perdido". De esta cosecha figuran aquí los que escogemos como representativos, y otros que ilustran puntos particulares. $\mathrm{El}$ orden corresponde al establecido en la edición de Wilson Follet de las poesías recogidas (Alfred Knopf, Nueva York, 1930), que contiene Los jinetes negros, La guerra es benigna, los diez poemas de amor titulados Intriga y los tres poemas hallados en 1928; y el número de cada poema indica el que lleva en la sección respectiva.

Las traducciones son tan exactas como es posible. Hemos procurado respetar el sentimiento del autor, su actitud poética, el efecto general de los poemas, el significado llano de las frases y la forma er: que aparecen impresos. No hemos procurado imitar las cadencias rítmicas (de que depende en gran parte, por supuesto, el efecto musical), por juzgarlo imposible. 


\section{Los poemas}

Jinetes II.

Tres pajaritos, en fila sentados, pensativos.

Un hombre pasó cerca de ellos, miráronse los pajaritos discretamente.

Dijeron: - Cree que puede cantar. Soltaron una carcajada.

$Y$ con caritas picarescas

le contemplaron.

Eran muy curiosos,

esos pajaritos sentados en fila.

Jinetes III.

En el desierto

vi un hombre en cuclillas, desnudo, perdido como una bestia, que tenía el corazón en las manos

y comía de él.

Dije: - ¿Es bueno, amigo?

-Es amargo, amargo —respondió-,

pero me gusta

porque es amargo,

y porque es mi corazón.

Jinetes XVIII.

En el paraíso

unos tallitos de hierba estaban delante de Dios.

—Qué hicísteis?

Entonces todos, menos uno. empezaron a relatar ardientemente

los méritos de sus vidas.

El otro se quedó un poco atrás, avergonzado.

Pasado un rato, Dios dijo:

-Y tú ¿qué hiciste? 
El tallito contestó: -Oh Señor mio,

la memoria me es amarga,

pues si hice actos buenos

los ignoro.

Entonces Dios, en todo su esplendor.

se alzó de su trono.

- OOh tú, el mejor tallito de hierba! - dijo El.

Jinetes XIX.

Un dios airado

golpeaba a un hombre;

le abofeteó ruidosamente

dándole puñetazos atronadores

que sonaron y ondearon por la tierra.

Toda la gente acudió corriendo a cual más.

E1 hombre chilló y luchó,

y le mordió los pies al dios.

La gente gritó:

-iAy, qué hombre tan malvado!

y también:

-iAy, qué dios tan tremendo!

Jinetes XXIV.

Vi un hombre que corría tras del horizonte; dió varias vueltas tras de él.

Aquello me conturbó;

fui hacia el hombre y le dije:

-Es inútil:

jamás podrás...

-Mientes- gritó,

y siguió corriendo.

\section{Jinetes XXXII,}

Dos o tres ángeles

se acercaron a la tierra.

Vieron una iglesia gorda.

Arroyuelos negros de gente

venían y entraban continuamente.

$Y$ los ángeles se inquietaton

queriendo saber por qué iba la gente así

y por qué permanecía tanto tiempo dentro. 
Jinetes XLII.

Yo andaba por un desierto.

Y grité:

-Oh Dios, isácame de aquí!

Una voz dijo: -No es un desierto.

Yo exclamé: —Sí, pero...

la arena, el calor, el horizonte vacío...

Una voz dijo: -No es un desierto.

dinetes XLVI.

Muchos diablos rojos corrian de mi corazón a la página.

Eran tan menudos

que la pluma podía destriparlos.

$Y$ muchos agonizaron en la tinta.

Qué extraño era

escribir en este fango rojo

de cosas salidas de mí corazón.

\section{Jinetes LI.}

Un hombre se presentó ante un Dios ajeno-

el Dios de muchos hombres, tristemente sabio.

$Y$ la Deidad tronó ruidosamente,

gorda de coraje, y bufando:

-Arrodillate, mortal, y humillate;

rebájate $y$ ofrece homenaje

a Mi Majestad Sublime en particular.

El hombre huyó.

Después el hombre fué a otro Dios-

el Dios de sus pensamientos íntimos.

$Y$ éste le miró

con ojos muelles

encendidos de infinita comprensión,

y dijo: - Pobre hijo mío!

Jinetes LVIII.

Un sabio discurría brillantemente.

Ante él, dos imágenes:

-Pues ésta es un diablo.

$\mathrm{y}$ ésta soy yo. 
Se apartó un poco.

Entonces un discípulo socarrón

las cambió de posición.

Volvióse el sabio:

-Pues éste es un diablo,

y ésta soy yo.

Los discípulos se sentaron gesticulando

divertidos con el juego.

Pero el sabio era un sabio.

Jinetes LXVI.

Si yo me quitase este andrajoso abrigo

$y$ entrase libre en el potente cielo;

si allá no hallase nada

sino un azul vasto,

sin eco ni sentido-

entonces ¿qué?

La guerta es benigna I.

No llores, muchacha, que la guerra es benigna.

Porque tu amante las frenéticas manos extendió hacia el cielo y el caballo espantado corrió adelante, solo,

no llores.

La guerra es benigna.

Tambores del regimiento, roncos, zumbantes,

almas pequeñas que tienen sed de luchas,

estos hombres nacieron para marchar y morir.

La gloria sin explicación vuela sobre ellos;

magno es el dios de las batallas, magno, y su reino--

un campo donde yacen mil cadáveres.

No llores, niñito, que la guerra es benigna.

Porque tu padre murió en las trincheras amarillas, sintió rabia en el pecho, tragó y murió,

no llores.

La guerra es benigna.

Bandera del regimiento, veloz, fogosa,

águila de cresta de rojo $\mathrm{y}$ de oro,

estos hombres nacieron para marchar $y$ morir.

Señaladles a ellos las excelencias de la matanza

y un campo donde yacen mil cadáveres. 
Madre cuyo corazón colgaba humilde como un botón en la mortaja clara y espléndida de tu hijo, no llores.

La guerra es benigna.

\section{La guerra $\mathrm{V}$.}

- ¿Has hecho jamás un hombre justo?

-Oh, he hecho tres - contestó Dios.

-Pero dos de ellos han muerto.

y el tercero...

¡Escucha! ¡Escucha!

¡Y oirás el golpe de su derrota!

\section{La guerta $\mathrm{X}$.}

¿Me dices que Dios es esto?

Te digo que esto es una lista impresa, una vela encendida, y un asno.

\section{La guerta XIII.}

El caminante, al ver el sendeto de la Verdad, quedó asombrado.

Estaba muy cubierto de maleza.

-Ja -dijo él-,

veo que hace mucho tiempo

que no pasa nadie por aquí.

Después vió que cada hierbajo

era cuchillo singular.

-Pues - barbulló al fin-

sin duda hay otros caminos.

La guerra XXI.

Un hombre le dijo al universo:

-i Señor, yo existo:

- Sin embargo - replicó el universo-,

tal hecho no ha creado en mí

sentido alguno de obligación.

La guetra XXV.

Cada fulgor era una voz, una voz de linterna- 
en cancioncitas de carmin, violado, verde, oro.

Un coro de colores cruzó por el agua;

cesó de ondear la hoja-sombra maravillosa, ningún pino canturreó en los collados,

la noche azul era en otra parte un silencio, cuando cruzó el coro de colores por el agua, cancioncitas de carmin, violado, verde, oro.

Piedrecillas relucientes echados. sobre el plano obscuro del anochecer cantan buenos romances de Dios y de la eternidad, con descanso de almas. Sacerdotillos, padrecitos santos, nadie puede dudar de la verdad de vuestros himnos cuando el coro maravilloso cruza por el agua, canciones de carmín, violado, verde, azul.

\section{Intriga IX.}

El amor me encontró a mediodía

(atrevido diablejo, que dejó sus noches sombreadas por desafiar la luz del sol) y le vi entonces claramente y supe que era un chapucero, un chapucero estúpido, ciego, que sonrie neciamente, y les rompe el corazón a las gentes valientes mientras él, llora duelos, quiebra su tazón.

$Y$ le maldije; maldijele de un lado a otro, atrás y adelante, en todos los nichos de su mente.

Pero al fin se rió él, y señaló mi pecho donde todavia un corazón latía para ti, querida.

Tres poemas I.

Un hombre a flote, agarrado de un mástil delgado, un horizonte más pequeño que la boca de una botella, olas puntiagudas alzando tiendas negras y latigantes, el lamento cercano de espuma en círculos.

Dios es impasible. 
El subir y bajar incesante del mar y el gruñir sempiterno de sus olas. el hundirse, verde, hirviente, sin fin, el alzarse completo a medias.

Dios es impasible.

Los mares están en el hueco de La Mano; los océanos pudieran convertirse en espuma $y$ caer en lluvia por las estrellas a causa de un gesto de compasión hacia una criatura.

Los océanos pudieran hacerse ceniza gris, morir con un gemido largo y un rugido entre el tumulto de los peces y los gritos de las naves, si La Mano llamase a sus ratones. Un horizonte más pequeño que la gorra de un asesino, tumultos negros, palpitantes, un cielo volteando, borracho, y ningún cielo, una mano pálida deslizándose del mástil pulido.

Dios es impasible.

El soplo de un hálito que aprisiona el aire:

un rostro que besa el agua-muerte, el ladearse cansado, lento, de una mano perdida y el mar, el mar moviéndose, el mar.

Dios es impasible.

\section{El significado de Crane}

El mundo nunca ha estado seguro de cómo recibir a Crane, y con buena razón: sus propósitos no fueron los tusuales. El tuvo el infortunio de hallar la edad no muy dispuesta a oír lo que él tenía que decir. Los gustos del día, las normas de conducta, tenían por base el victorianismo. La poesía nacional, es verdad, no había permanecido estática, sin dar un paso. La antigua escuela de los románticos a la europea - Longfellow, Lowell, Qhittier, Bryant, Bayard Taylor- dió lugar a dos tendencias distintas. Una, que incluye a T. B. Aldrich, Stoddard, Stedman y otros, se contentó con versificar de manera cada vez más constreñida a la tradición. Con los ojos 
pegados al pasado y a Europa, ni se dieron cuenta de la inmensa riqueza literaria que los rodeaba. A los grandes cambios que sucedieron a nuestra Guerra de Secesión en los campos del gobierno, la economía y la sociología, la reacción de estos escritores fué la de mirar resueltamente al este - Nueva Inglaterra-, empeñarse en decir lo antiguo, lo clásico, lo universal, de manera que no pecasen de novedad ni de conexión alguna con la vida real. Nos dieron ecos de la antigua música; nunca llegaron a tocar la vida. Pero la tendencia que ellos siguieron no murió muy fácilmente. ¿Quién dirá que aun hoy la lectura de Browning y de Tennyson - sin mencionar a los norteamericanos que los imitaron- no tiene su efecto en los gustos y en las costumbres de la "gente bien"?

La segunda escuela, precedida por la mayor parte de la plebe -Walt Whitman, Bret Harte, Joaquín Miller, James Whitcomb Riley-, se echó por el rumbo que había de conducir al fin a una literatura verdaderamente americana. Estos hombres (con muchos otros) vinieron casi todos del oeste, o habian bebido el espíritu de las tierras situadas más allá de los Alleghanys del Misisipí, aun de las Montañas Rocosas. Ellos vieron un ideal nuevo, y lo siguieron; escribir acerca de sus conciudadanos - sus pensamientos, sus problemas, las cosas de su vida diaria y su escenario. Esta tendencia fué fuerte en la prosa; dió lugar a un naturalismo americano nuevo en las novelas de William Dean Howells y del mismo Crane, a cuentos en dialecto por Joel Chandler Harris, Mark Twain y otros, y al cuento de color local en Harte, George Washington Cable, Mary E. Wilkins Freeman y muchos otros. En la poesía produjo romances populares e imitaciones de ellos de John Hay, Harte, y Miller; poesía en dialecto de Riley, Irwin Russel y otros; y la explosión democrática de Whitman en sus Hojas de hierba, lanzado al mundo por primera vez en 1892, el año de la muerte del patriarca.

Por alguna razón, la prosa continuó su desarrollo realístico - Hamlin Garland, Frank Norris, Theodore Dreiser, etc.-, mientras que la poesía todavía continuaba indecisa. A pesar de Whitman, que predicó por medio siglo la fraternidad del hombre y la libertad en la forma de la poesía; a pesar de Emily Dickinson, quien, encerrada en Nueva Inglaterra, dió al mundo su visión quieta pero tremenda en poesía imaginista y precisamente cuando esto faltaba para apoyar el nuevo movimiento; a pesar de Richard Hovey y Bliss Carman con sus Canciones de Vagabundia que fueron una alba falsa; 
a pesar de la influencia de la prosa; y en contra de Edwin Markham, William Vaughan Moody y Edwin Arlington Robinson, esforzándose por nacer, y de la "poesía nueva" que había de seguirlos - a pesar de todo esto la década 1890-1900 continuó poéticamente indecisa. De hecho, hubo un nuevo ímpetu de reacción (John B. Tabb, Richard Watson Gilder, Frank Dempster Sherman - recreadores de lo recreado). La moralidad de entonces parece que erá bastante conservadora: el padre ocupado en los negocios, la madre sentada en la sala o de visita, y toda la familia en la iglesia el domingo así se cumplían los deberes sociales. La década era de terciopelo rojo y oropel, y tan lista estaba para recibir a Crane como hubiera estado para aplaudir, digamos, algunos de los bailes modernos.

Especialmente los críticos. Cuando salió el libro Los jinetes negros, en 1895, su opinión general fué que Crane era demente e inmoral. Hubo sólo dos reseñas favorables - las de las revistas Bookman y Lotus. El fallo fué casi universal contra Crane. Y Crane a esta sazón no era un nadie. Su novela Divisa roja del valor, vendida a un sindicato en 1894 y publicada en series en la Philadelphia Press, había dado a conocer muy favorablemente al joven autor; la novela la iba a publicar en forma de libro la casa editorial Appleton, que la habia comprado en 1894 y la publicó en octubre de 1895. Maggie, publicada desde 1893, había conseguido al fin las alabanzas más ardientes de William Dean Howells, tal vez el literato más eminente de la época. Otros cuentos y bosquejos habian aparecido, y el público literario ya conocía a Crane y lo estimaba escritor casi único en su campo. Y las poesías habian salido dedicadas a Hamlin Garland, figura muy importante entre los literatos y que había protegido a Crane con interés paterno.

Semejante fué la acogida de La guerra es benigna, en 1899. Para esta fecha Crane había producido "El bote abierto" y muchos otros cuentos de valor incliscutible; Inglaterra lo había aceptado como autor distinguido, según el testimonio de Ford Madox Ford. Pero todavía sus contemporáneos en los Estados Unidos no comprendieron este verso nuevo y diferente. Los críticos se pasmaron de nuevo. Uno, de Boston, escribió: "El sentido del humor del señor Crane es de un tipo misterioso. Nos muestra intencionalmente los horrores de la guerra y no obstante titula su libro La guerra es benigna". No comprendieron. 
¿Después? La confusión continuó. Harriet Monroe, que debió comprender a Crane, parece que no quería comprenderlo. Ella, fundadora $\mathrm{y}$ por muchos años editora de Poetry: A Magazine of Verse - revista que unió a los poetas que escribían experimentalmente, como no lo hizo otra revista ni antes ni después, y que sirvió de foco para el grupo que surgió en los años 1913-1917 (Vachel Lindsay, Carl Sandburg, Amy Lowell, Robert Frost, Edgar Lee Masters, John Gould Fletcher). Y Harriet Monroe, al escribir en Poetry (junio de 1919), le achaca sentimientos falsos y moralidad victoriana "y le niega sitio entre los de "la poesía nueva". En apoyo directo de su dictamen cita dos poemas, ambos de Los jinetes negros:

Jinetes $\mathrm{XXX}$.

Supongamos que yo tuviese el valor

de permitir que una espada roja de virtud

me clavase el corazón,

derramando sobre la mala hierba del suelo

mi sangre pecadora.

¿Qué pueden ustedes ofrecerme?

¿Un castillo con jardines?

¿Un reino lleno de flores?

¿Qué? ¿una esperanza?

Pues ¡largo todos de aquí con su espada de virtud!

Este poema, dice la señorita Monroe, (1) es típico de los contenidos en Los jinetes negros; (2) es común en el sentimiento: y (3) no tiene en el movimiento rítmico el sello especial que es la marca del maestro. Estos tres puntos creemos que serán negados por algunos, especialmente el primero, que nos parece mal juzgado, y el tercero, que es muy difícil averiguar. El segundo poema:

Jinetes XXXIV.

Yo estaba en una carretera

$-\mathrm{y}$ he aqui que vinieton muchos buhoneros extraños.

Cada uno me hizo señas mostrándome idolillos y diciendo:

-Esta es la imagen de mi Dios;

pues éste es el Dios que yo prefiern. 


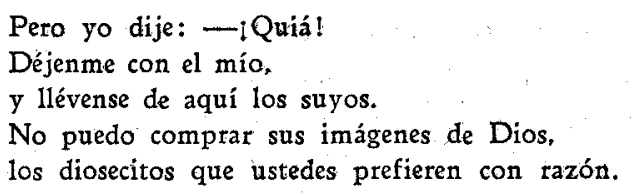

Este sí que encarna un pensamiento poco profundo y un sentimiento poco elevado. Pero con él clasifica la señorita Monroe muchos otros, incluyendo los números X, XVIII y XIX, aqui traducidos. Parece que escogió precisamente los ejemplos que quiso para condenar el libro. Monroe reconoció los méritos de Crane como prosista, e imprimió con su aprobación el poema "La guerra es benigna" (es decir, el número I de esta serie), que, según ella, es el mejor de los poemas de Crane. También alaba tres o cuatro detalles y fragmentos de poemas. Pero a Crane como poeta lo rechaza definitivamente del número de los selectos. En la primera edición (1917) de su antología La poesía nueva: Antología de versos del siglo $X X$ en inglés, que incluye sólo poemas posteriores a 1900, la señorita Monroe no menciona a Crane; pero en la segunda (1923), en la introducción, califica a Crane de "moderno del siglo XIX" y cita su poema "La guerra es benigna", diciendo que, a no ser por las restricciones del tiempo y de su muerte, ella hubiera tenido que incluir a Crane en la antología.

Parece que con el correr de los años empezamos a darle a Crane mejor acogida. Selecciones de su poesía aparecen en los libros de texto y en antologías como la de Louis Untermeyer o la de Christopher Morley, con juicios apreciativos. Carl Van Doren alaba a Crane, diciendo lo que dicen varios otros en casi las mismas palabras, afirmando que la literatura verdaderamente norteamericana empezó con Crane. Ford Madox Ford; en su libro Retratos sacados de la vida, se esfuerza en probar esto. Muchos lo alaban por sus novelas y cuentos. Edward Garnet, crítico inglés, escribió en 1921 que si América no estima a Crane, ella no merece tener artistas literarios. El poeta Alfred Kreymborg, en su Historia de la poesía americana (1934), dice que el verso de Crane es de interés histórico. más bien que intrínseco, afirmando también que el movimiento del verso libre empezó con Crane y que él es el precursor de los imaginistas. Amy Lowell, que estima a Crane como muy importante en la poesía norteamericana, dice que sus treinta años de olvido los debe 
Crane a los diferentes editores, que presentaron sus poemas en forma mal calculada para ganarles consideración.

¿Cuáles son las caracteristicas de los poemas de Crane? Algunas que deben mencionarse son: $1^{\mathrm{a}}$, su uso del verso libre; $2^{\mathrm{a}}$, varias tendencias imaginistas; $3^{\mathrm{a}}$, su insistencia en la validez de su propia visión del universo; y $4^{\mathrm{a}}$, los efectos originales que obtuvo en sus ritmos y, más aún, en su dicción. $\mathrm{El}$ verso libre, por supuesto, no era nuevo. Whitman lo había empleado y predicado desde 1855. Anna Bracket había escrito sonetos sin rima, Emily Dickinson había experimentado con éxito en rimas a medias. Existía, por supuesto, la larga y gloriosa tradición del verso blanco, instrumento de maravilloso poder en manos de Milton y bien empleado por Tennyson, Matthew Arnold, Browning y muchos otros; y Milton (en Samson Agonistes), William E. Henley (en London Voluntaries 1890-1892) y Matthew Arnold (en "Philomela") en Inglaterra habían empleado el verso libre. Los franceses habían empleado el verso libre propiamente dicho, ya unos cuantos años antes de Los jinetes negros. Pero Whitman había sido una voz clamando en el desierto por cuarenta años, y su verso - sonoro, masculino, tremendo, con recuerdos de nuestra Biblia inglesa - fué algo diferente del instrumento ágil, saltante, de Crane. Las frágiles cadencias de Emily Dickinson -insuperadas en su género, y que Crane conocía y admiraba mucho- se diferencian tanto de los ritmos de Crane como del verso blanco tradicional. Es de suponer que Crane conocía los poemas de Milton, Arnold y Henley. Otros experimentadores de importancia, de habla inglesa, no los había. Se duda que Crane aun tuviese noticia de los innovadores franceses. Tampoco conocía a los chinos ni a los japoneses, cuyos poemas recuerdan muchas veces.

Es interesante ver los puntos en que Crane se anticipó a la escuela imaginista. El credo de tal grupo, promulgado por Amy Lowell en su antología Algunos poetas imaginistas (191.5), es éste, en forma breve:

1. Usar el lenguaje del habla común, pero siempre la palabra exacta, no la palabra meramente decorativa.

2. Crear ritmos nuevos para expresar sentimientos nuevos. Esto no implica el verso libre, pero si muchas veces va a resultar en él.

3. Dejar una libertad absoluta para escoger temas. 
4. Presentar una imagen particular. La poesia no debe tratar de vaguedades.

5. Producir poesía que sea firme y clara, no indefinida.

6. Concentrar el poema en pocas líneas.

$Y$ en su libro Tendencias en la moderna poesía americana (1917), la señorita Lowell añade:

\section{Emplear mucho la sugestión.}

Estos preceptos no eran nuevos, ni to dijeron los imaginistas. Admitieron la influencia de muchos poetas - Safo, Catulo, Dante, Chaucer, Villon y Heine, y más particularmente la Biblia hebrea y la versión inglesa del Rey Jacobo, William Blake, Walt Whitman, Emily Dickinson, y varios franceses desde Verlaine y Mallarmé hasta Remy de Gourmont, Gustave Kahn, Emile Verhaeren, Paul Fort, André Spire y otros. En la literatura norteamericana Emily Dickinson ya había anticipado los preceptos más importantes a todos. $\mathrm{Y}$ es cierto que la poesía de Crane llegó tan cerca del imaginismo, como la de los imaginistas mismos; pues ellos empezaron en muy pocos años -aun la misma Amy Lowell- a violar las reglas que establecieron.

No nos proponemos hacer aquí un análisis de los poemas de Crane para probar que debemos darle el honor, si tal es, de haber sido un precursor del imaginismo. Creemos que pudiera hacerse tal análisis, y que la prueba daría este resultado: (1) Crane habla el idioma común, sencillo; usa mucho el diálogo. Tiene genio para escoger la palabra exacta ("un cielo olvidado de azul tímido") ; sus metáforas golpean. (2) Sus ritmos y el uso del verso libre son absolutamente nuevos y únicos. (3) Sus temas, si bien no muy variados, incluyen algunos de índole tuniversal y muchos mortificaron a sus contemporáneos. (4) Crane no abusa de las imágenes como los imaginistas. El punto central de su poema suele ser una idea o una observación más bien que un sentimiento evocado por una imagen. (5) Sus poesías son absolutamente desnudas. (6) La mayor parte de sus poemas dan una idea, o fijan una actitud, en cuatro o cinco frases cortas. (7) En la sugestión Crane revela maestría muchas veces.

Amy Lowell, en la introducción que escribió para el volumen VI de las Obras completas de Crane (1926), dice que Crane debió 
ser el padre de la poesía nueva; pero que no lo fué sencillamente porque los más de los escritores de este grupo, basándose en los franceses y en William Blake, ignoraban la obra de Crane. Pero ella lo califica, en el mismo párrafo, de "eslabón importante" en la cadena de la poesía norteamericana.

Muchos dirían (como muchos lo han dicho) que Crane fué ateo, o por lo menos agnóstico. Se ha expresado también que escribió sus fulminaciones expresamente para llamar la atención. No lo sabemos. Muy pocos son los hombres que han logrado revelar en sus escritos su creencia íntima y verdadera de Dios. El lector sin prejuicios que lea todos los poemas hallará - así lo creemos- que hay tanto de positivo como de negativo en ellos, y que la duda que así se expresa tenía que expresarse. Esta es precisamente una de las contribuciones más considerables que hizo Crane. Déspués de él, los poetas norteamericanos se hallaron en estado de hablar francamente de sus pensamientos acerca de st1 Dios; antes no había existido tal posibilidad. Si escribió Crane para hacer escándalo tampoco lo sabemos, no podemos saberlo, ni pudiéramos saberlo si él mismo volviera a la tierra. Sí sabemos que, al ver las críticas de Los jinetes negros, exclamó: "Sí, muchos de estos poemas son bastante estúpidos; pero los tenía en mí, y me alegro de haberlos dicho".

Su estilo permanece único hasta hoy. Ello no quiere decir que no haya habido quien imitase la forma corta y sencillísima de sus fábulas, sus adjetivos increíbles y sus metáforas atrevidas, y, sobre todo, el ritmo de sus versos. En su tiempo su estilo creó sensación, y después ha ejercido un efecto muy grande en la métrica inglesa.

Para apreciar la parte que tuvo Crane en la emancipación de las letras norteamericanas del romanticismo senil de la última mitad del siglo XIX, conviene hacer una lista de nombres y fechas. La que aquí damos tiene el objeto de mostrar tal desarrollo, en términos de los escritores más importantes, sean realistas, imaginistas, o de cualquiera tendencia o escuela especial. La evolución que ella señala esmuy general y se refiere sólo a la lucha para librar la literatura. norteamericana de los restos de una tradición ya moribunda y para traer a luz un instrumento de expresión más propio a los tiempos modernos. Faltan muchísimos nombres: hemos escogido los que nos parecen representativos. De cada autor se dan una o más obras, con fechas; tales obras son las primeras importantes de tal autor - es decir, importantes en relación con la tendencia que estudiamos. 


\section{CRONOLOGIA}

\section{Publicación poética importante}

1. Walt Whitman (1819-1892)

Leaves of Grass. . . . . . . . . . . . . 1855

2. Mark Twain -Samuel Clemens- $(1835-1910)$

"Jumping Frog". . . . . . . . . . . . . . . . 1865

Tom Sawyer, Life on the Mississippi,

Huckleberry Finn. . . . . . . . . . . . . 1876-1884

3. William Dean Howells (1837-1920)

A Modern Instance. . . . . . . . . . . . . . . 1882

Rise of Siles Laphan. . . . . . . . . ..... 1885

4. Emily Dickinson (1830-1886)

Poems, Primera serie. . . . . . . . . . . . 1890

5. Hamlin Garland (1860-1940)

Main-Travelled Roads. ............... 1891

6. Amy Lowell (1874-1925)

Sword Blades and Poppy Seed............. 1914

7. Stephen Crane (1871-1900)

The Black Riders and Other Lines........... 1895

War is Kind. . . . . . . . . . . . . . . . . 1899

8. "The New Poetry" - grupo centralizado en Harriet Monroe y la revista Poetry: A Magazine of Verse; incluye a Carl Sandburg, Vachel Lindsay, Amy Lowell, Robert Frost, Edgar Lee Masters, Edwin Arlington Robinson, John Gould Fletcher $y$ otros.

9. Vachel Lindsay (1879-1913)

"General William Booth Enters Heaven". . . . . . 1913

10. Carl Sandburg (1878 - )

"Chicago"....................... 1914

Chicago Poems ................... 1916 
Para la comparación de fechas, pongamos una lista semejante de escritores no norteamericanos, que han influíclo en este desarrollo $u$ otro similar.

11. Simbolismo francés (Verlaine, Mallarmé, etc.) ... 1855 y después.

12. Verso libre francés (Gustave Kahn, después Jules Laforgue, Paul Fort, etc.) . . . . . . . . 1887 y después.

13. Rubén Dario (1867-1916)

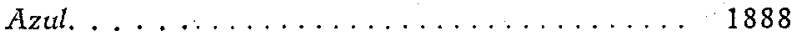

Prosas profanas. ................. 1896

14. William Ernest Henley (1849-1903)

London Voluntaries . . . . . . . . . . . . . . 1880-1892

15. Ezra Pound (1885 - )

Des imagistes. .................. 1914

16. Juan Ramón Jiménez (1881 - )

- Diario de un poeta recién casado........... 1917

La obra de Walt Whitman la conocía Crane, por supuesto; y no cabe duda de que influyó poderosamente sobre él. La influencia de Mark Twain hacia el realismo creemos que es general en toda la literatura norteamericana posterior a él; Crane admiró alguna parte de su obra solamente. A Howells, que realmente le abrió el camino al realismo en este país, lo conocía Crane personalmente, como a Garland; los dos lo ayudaron sólidamente. A los ingleses (William E. Henley, Oscar Wilde, Ernest Dowson - los. "decadentes" de 1890-1900) indudablemente los conocía, pero sin duda no los estimaba en mucho.

Si prestamos atención particularmente a la forma más bien que a la filosofía de sus poemas, tampoco es posible indicar una fuente determinada para Crane. Conocía y admiraba la obra de Emily Dickinson y sus poesías lo inspiraron a experimentar él mismo. Es improbable que tuviese noticias de los franceses que hacían tanto en el campo de la experimentación con las formas; y no leía eí español. Mưchos creen (entre ellos Amy Lowell) que sus ritmos, sus imágenes, su empleo del paralelismo y de la parábola vienen directamente de la Biblia; ello parece muty probable. 
Vale la pena ver cómo escribía Crane. Su amigo y protector Hamlin Garland ha dado la descripción clásica: Crane llegó un día al cuarto de Garland y le mostró una docena de los poemitas que se publicaron después en Los jinetes negros. Garland leyó algunos. Según él:

Después de leer estas líneas extraordinarias, alcé la mirada y pregunté gravemente:

- ¿Y usted escribió esto?

- Sí.

- ¿Cuándo?

- Esta mañana - contestó él, y poniéndose la punta del dedo en la sien derecha, añadió con gracia: -Tengo cuatro o cinco más coleccionados aquí arriba... todo lo que necesitan es que los saque; pero no puedo escribir entre esos indios. 3

- Siéntese usted aquí y sáquelos- le sugerí yo.

Al instante se sentó a mi mesa y transcribió varios otros poemas, algunos de los más fuertes e imaginativos de la serie. Escribió sin vacilar, en una escritura clara a maravilla, con líneas y espacios perfectos, precisamente como si copiase algo ya escrito y puesto delante de sus ojos.

Según su explicación, la composición de estas líneas fué un proceso enteramente automático $\mathrm{y}$ subconsciente; y yo, estando a la sazón muy interesado en los fenómenos psíquicos supernormales, quedé, naturalmente, bastante impresionado por el aire que tenía el poeta de hallarse alejado de lo que hacía. Ello fué precisamente como si algán espititu ajeno tindiese estas lineas por su mano como medio.

- Hay un espectro a su espalda - le dije con una seriedad socarrona-, pero no es el espectro que le dió La divisa roja del valor. Este es un espiritu de agnosticismo militante... un espectro satírico.

Yo hablaba por supuesto sólo medio en serio cuando dije esto; pero al mismo tiempo era evidente que su composición (aun ảl proceder a puntuar) se realizó subconscientemente y que el escribir en el papel sus poemas era para él como transcribir de una página impresa. Me dijo que las primeras páginas de La divisa roja del valor le vinieron precisamente de la misma manera, cada palabra en su lugar, cada coma, cada punto ya fijado.

Durante unos cuantos dias vino regularmente trayendo estos fragmentos curiosos, y entonces poco a poco el número de los poemas disminuyó hasta que tenía sólo uno o dos. Por fin una noche, sentado yo en el tocador de Herne en el Teatro Daly, el poeta (a quien también le habían concedido la libertad de la casa) entró precipitadamente y dijo, algo excitado: - Tengo otro - y me entregó la más larga y la mejor de sus composiciones rítmicas sin rima: 
Jinetes XLIX.

Yo estaba de pie, meditando, en un mundo negro, sin saber adónde dirigir los pies.

$Y$ vi el rápido caudal de hombres

fluyendo perpetuamente,

lleno de caras vehementes,

un torrente de deseo.

Los llamé:

- ¿Adónde vais? ¿Qué veis?

Mil voces me llamaron.

Mil dedos señalaron.

- Mira tú! iAllí!

No sé de ello.

- Pero be aquí que en el cielo lejano brilló un fulgot inefable, divino-

una visión pintada en paños de tumba;

y algunas veces era,

$y$ algunas veces no era.

Yo dudé.

Entonces del caudal

vinieron voces rugientes,

impacientes:

- Mira tú! ¡Allí!

Y otra vez vi,

y salté sin vacilar

y agitéme y encolericéme

y extendi los dedos agarradores.

Los collados duros me laceraron las carnes;

las veredas me mordieron los pies.

Pot fin volví a mirar.

Ningún fulgor en el cielo lejano,

inefable, divino;

ninguna visión pintada en paños de tumba:

y siempre mis doloridos ojos ansiando la luz.

Entonces grité desesperado:

- iNada veo! Oh, ¿a dónde me dirijo?

El torrente volvió otra vez sus caras:

-iMira tá! iAllí!

$\mathrm{Y}$ ante la ceguedad de mi alma

gritaron:

-iBobo! iTonto! iNecio! 


\footnotetext{
- ¿Hay más ahí arriba? - pregunté, señalándole la cabeza.

-No - contestó él con un poco de melancolía-, se han agotado . . el sitio está ya vacío.

$Y$ en efecto, así fué. El no escribió más que estas líneas; y cuando șalió el libro Los jinetes negros, yo quedé conmovido al hallar que estaba dedicado a mí. 4
}

Otro tanto dice Joseph Conrad de la manera de Crane de escribir prosa. Conrad afirma que lo vió sentarse ante un pliego blanco, escribir la primera línea en seguida, y continuar sin apresurarse y sin vacilar por un par de horas. Conrad llama a esto mentalidad más bien que inspiración; y dice que, como todos los escritores, Crane no pudo siempre contar con el fluir constante de las palabras. Amy Lowell analiza muy bien el genio poético de Crane en un par de frases, en la introducción que escribió para sus poemas. Ella cree que, en efecto, Crane tenía dentro de sí lo que equivale a un depósito, que podía muy bien agotarse, y que quedaba entonces vacío hasta que Crane, en el curso de la vida, tenía tiempo de ver, pensar y sentir bastante para llenarlo de nuevo.

Ignoramos la génesis de la mayor parte de los poemas de Crane. Es de suponer que se hallaba en algo que él vió, o en algún pensamiento errante. Thomas Beer, en su biografía de Crane, indica que el origen del poema que dió el título a Los jinetes negros, y que es el primero de la colección asi titulada, fué una pesadilla que tuvo Crane varias noches seguidas, siendo niño. El poema:

Jinetes I.

Jinetes negros venían del mar.

Habia choque y estrépito de lanzas y escudos,

$y$ estrépito $y$ choque de cascos y talones,

gritos desenfrenados y el ondear de cabellos

en el tropel hacia el viento:

así el cabalgar del Pecado.

El poema "Tres poemas-I", es muy fácil que se hubiese inspirado en la experiencia que tuvo Crane en un naufragio al volver de Cuba.

Respecto a otro, Jinetes LXVII, Beer muestra haber nacido en el Bowery: 
Dios yacia muerto en el cielo; los ángeles entonaron el himno del final; vientos purpúreos pasaron gimiendo, sus alas goteando

de sangre

que cayó a la tierra.

La sangre - cosa de lamentos-

se ennegreció y hundió.

Entonces de las cavernas lejanas

de pecados muertos

salieron monstruos, lívidos de deseo.

Ellos pelearon,

riñeron por el mundo,

un bocado.

Pero entre todas las tristezas esto fué lo triste:

los brazos de una mujer trataron de defender

la cabeza de un hombre dormido

de la boca de la bestia final.

El cuadro vivo fué el de una joven de la calle que le cubría la cabeza a un alcahuete borracho para protegerlo de un grupo de salteadores que trataban de hacerle pedazos la cara a puntapiés.

IV

El poeta

Entiendo que un hombre nace en el mundo con su propio par de ojos, $y$ de ninguna manera es responsable por su visión - sólo es responsable por su honradez personal. El mantenerme junto a esta hontadez personal es mi ambición suprema.

\section{STEPHEN CRANE}

¿Y cómo era Crane, el hombre que tan a fondo sintió los tuertos y agravios de este mundo imperfecto? Tenemos retratos de él. Lo representan alto, delgado, largo de rostro y sobre todo de nariz, con unos ojos que tienen dentro de sí hogueras vivas, medio ocultas por cierta expresión de indiferencia. Un infinito de comprensión 
debían de encerrar aquellos ojos, y más de un poco de desprecio y de disguisto - tal vez algo de temor. Sus amigos hablan de él de diversas maneras, pero todos le reconocen una cualidad irreal, fantástica. Parece que lo tuvieron por un sér no enteramente de este mundo. Ford Madox Ford, que lo conoció bien en Inglaterra, dice que no cabe mejor ejemplo del hecho de que los seres sobrenaturales visitan la tierra, en raras ocasiones. Todos se extrañan de la combinación de niño y sabio que ven en él.

Joseph Conrad, tal vez el mejor amigo de Crane en los últimos años de la vida de éste, hace constar muchas características importantes: la seriedad de Crane; su manera de hablar, muy despacio y sin cuidado; la delicadeza y finura que parecian ser innatas en él; su generosidad (cualidad que resultó trágica para él); su absoluta incapacidad de no ser sino sincero. Todos los que lo conocieron hablan de su afición a los caballos y a los perros. Quizá hallaba en los animales una sinceridad que correspondía a la suya, y que seguramente no existía en el mundo de los hombres. Un detalle interesante, contado por Conrad, es la fascinación que Crane sentía por el niño de los Conrad. Los dos - Crane y el niño que todavía no hablaba ni andaba - se sentaban mirándose con toda la seriedad del mundo, por una media hora entera. $Y$ que otra vez los dos se reían el uno del otro. $\mathrm{Y}$ dicen que la risa no era muy común en Stephen. ¿Otro caso de afinidad?

La envidia de algunos espíritus avellanados, contemporáneos de Crane, y su propia incapacidad para disimular, dieron lugar a toda una biografía apócrifa de él. Se ha afirmado que no podía escribir sino cuando estaba borracho. Se le ha achacado ser un seductor y adicto a las drogas. Su biógrafo, Thomas Beer, halla toda una pléyade de mentiras fantásticas - desde la de que fué hijo ilegítimo del presidente Grover Cleveland hasta la de su muerte en París víctima de delirium tremens. Todas las improbabilidades, imposibilidades y contradicciones del mundo, alegadas como verdades. $Y$ Stephen fué tan bonachón que acogió a su mesa y bajo su techo a muchos de sus mismos difamadores, sabiendo el mal servicio que le hacían. El casón baronial que mantenía en Brede, en Inglaterra, estaba lleno a todas horas de hombres que comían su pan mientras le quitaban el sosiego que tanto necesitaba, para su trabajo y para su salud. Stephen se quejó a su editor de que lo que tenía no era 
una casa, sino un hotel, en el que ningún huésped pagaba, pero no podía cerrar su puerta a nadie.

La suspicacia del público y las malicias de los chacales quedan completamente abolidas. Los hechos de su vida son bastante bien conocidos ahora, a pesar de la falta de evidencias contemporáneas impresas. Sabemos que bebía muy poco, y que su bebida ordinaria era la cerveza. Sabemos que no ingería drogas; apenas fumaba y sus amigos afirman que sólo lo hacia para tener algo entre los dedos. Ninguna evidencia tenemos de que fuese inmoral como hombre infiel ni como marido. Sabemos que murió de tuberculosis, contraida en sus días de corresponsal de guerra, en Cuba. El curso de su vida corrió así :

1871 10. de noviembre - nació en Newark, New Jersey, hijo décimo cuarto (y último) de un pastor metodista bueno y simple, y de una madre pía.

1880 - se le murió el padre; la madre tuvo que ganarse el pan, escribiendo para revistas religiosas.

1882-1888 - asistió a la escuela de Asbury Park, al Seminario de Pennington, $\mathrm{y}$ al Instituto (militar) del Rio Hudson, Claverack, Estado de Nueya York.

1888, Verano - trabajó para su hermano Townley, recogiendo artículos para los periódicos.

1889 - entró, para pasar un año, en el Colegio Lafayette; jugó al baseball, boxeó; estudió poco.

1890 - pasó un año en la Universidad (metodista) de Syracuse; allí capitaneó el equipo de baseball.

- se hizo corresponsal de La Tribuna, periódico de Nueva York, ayudándose asi para continuar su educación.

- se le murió la madre.

1891 - se fué a Nueva York a ganarse la vida sin conocimientos de literatura.

- se mantuvo muy pobremente vendiendo artículos a La Tribuna y a El Heraldo, viviendo en el Bowery.

- conoció a Hamlin Garland.

(septiembre) - tuvo su amorío con Miss Trent.

(diciembre) - escribió Maggie, en dos días.

1892 - el Century (redactor en jefe, Richard Watson Gilder) rechazó el manuscrito de Maggie.

- fué despedido de El Heraldo.

1893 - publicó Maggie: Muchacha de la calle con $\$ 1,000$ que pidió prestados a un hermano.

(mayo) - escribió La divisa roja del valot, "en diez noches". 
1894 - la casa Appleton compró La divisa toja.

1895 - se fué a Texas y a México, enviado por el sindicato de Bachiller para que escribiese su viaje.

(mayo) - Copeland y Day, Boston, y Heinemann, Londres, publicaron Los jinetes negros.

(octubre) - Appleton publicó La divisa roja del valor.

1895-1897 - escribió los poemas de La guerra es benigna.

1896 - fué enviado con la expedición de filibusteros a Cuba, para hacer exposición de ella para El Mundo y el Joutnal.

- raufragó de vuelta de Cuba, y vivió a la intemperie cuatro días en un bote abierto; aquí fué donde comenzó la tuberculosis de que murió.

- conoció a Cora Taylor en Jacksonville, Florida; ella fué una rubia bastante guapa, de familia socialmente inferior a la de Crane.

(25 de octubre?) - se casó (¿en Atenas?, ¿París?, ¿Londres?) con Cora Taylor. Ella siempre le fué devota.

- se fué a Inglaterra, y de allí a Grecia a presenciar la guerra grecoturca (enviado por la Westminster Gazette y el New York Jour$n a l)$.

1897 - vivió en Limpsfield Chart; mudóse a Oxted; mudóse otra vez a Brede Place, mansión del tiempo de la Reina Isabel.

- conoció a Conrad, y llegó a ser muy amigo suyo.

1898 - corrió la voz de que Crane era un seductor, que usaba morfina, y que no podía escribir cuando no estaba borracho - todas ficciones.

- se fué otra vez a Cuba como corresponsal de El Mundo (Nueva York) para relatar la guerra entre España y los Estados Unidos. Los despachos oficiales lo mencionan por su valor en el campo de batalla.

- volvió a Nueva York; pronto se hizo a la vela para Londres, disgustado con la gente chismosa.

- hizo planes para ir a Santa Helena como corresponsal de la Posta de la Mañana (de Londres), pero no pudo realizarlo a causa de hemorragias.

1900 - su esposa lo llevó precipitadamente a Badenweiler, en el Bosque Negro.

( 5 de junio) - murió en Badenweiler. Fué enterrado en Elizabeth, New Jersey.

Robert E. Lucky, Palo Alto, California. 


\section{Nota bibliográfica}

Toda la crítica consultada de Crane, así como todos los recuerdos y los estudios sobre él, están escritos en inglés, salvo un artículo en alemán sobre su técnica poética. Damos aquí una selección de los libros y artículos más interesantes y de más valor.

LIBROS:

1. Obras completas, publicadas por Knopf, Nueva York, 1926, con introducciones importantes por Sherwood Anderson, Thomas Beer, Wilson Follett, Amy Lowell, H. L. Mencken, William Lyon Phelps, Carl Van Doren, Joseph Hergesheimer, Willa Cather, y otros.

2. Bibliografías por Vincent Starrett, O. L. Griffith, y B. J. R. Stolper.

3. Thomas Beer, Stephen Crane. Knopf; Nueva York, 1923. La más detallada y mejor bibliografía; reimpresa en The Borzoi Reader, Knopf, 1936, con introducciones de Carl Van Doren y Joseph Conrad.

\section{ARTICULOS:}

1. Max J. Herzberg, "Stephen Crane". Encyclopaedia Britannica, 14a. edición. Bueno por sis detalles exactos.

2. Joseph Conrad, "Stephen Crane". Notes on Life and Letters, Doubleday, Nueva York, 1921. Recuerdos íntimos de un caro amigo.

3. Ford Madox Ford, "Stephen Crane". Portraits from Life. Lleno de interés, aunque equivocado en la cronología; contiene un buen retrato.

4. Hamlin Garland, "Stephen Crane as I Knew Him". Yale Review, abril de 1914; reimpreso con modificaciones en Garland, Roadside Neethings, Macmillan, Nueva York, 1930. Es lo mejor que tenemos sacerca de los años del autor principiante. 


\section{NOTAS}

1 Damos estos títulos en traducción española para no interrumpir la continuidad; las formas inglesas son "The Open Boat", The Red Badge of Coutrage, y Maggie: A Gitl of the Streets.

2 Amy Lowell considera. que Intriga es un poema largo; puede ser considerado así.

3 Los "indios" de que habló Crane eran los estudiantes de arte entre los cuales vivía, en el Bowery de Nueva York.

4 De Hamlin Garland, "Stephen Crane as I Knew Him", en Yale Review, abril de 1914; y de Hamlin Garland, Roadside Meetings. Con permiso de The Macmillan Company, editores. El mismo asunto ya lo había tratado Garland en 1900, en la revista Booklover pata el otoño de aquel año. 
